\title{
Importance of the Phase Diagram in Lyocell Fiber Spinning
}

\author{
Kunal Singha \\ Department of Textile Technology, Panipat Institute of Engineering \& Technology, Harayana, India
}

\begin{abstract}
The lyocell fiber is become very popular in the recent time among the researcher due to its higher strength, rigid crystalline morphology and its proximity towards to cotton. Lyocell fiber gives higher mechanical modulus which substantially makes it an effective material for use in different biometerials, paper industry, nonwoven fabric or even in packaging purpose. The spinning of this kind of fiber is very challenging due to its several composite steps like- NMMO preparation (raw material), preparation of a proper solvent phase of NMMO-water system, spin extrusion etc. we can improve the quality and sustainability of this fiber product by a suitable judgment of the phase diagram of the spinning system (charge) and also increase in production.
\end{abstract}

Keywords Lyocell Fiber, Biometerials, Paper Industry, Nonwoven Fabric, Packaging, NMMO-Water System, Phase Diagram

\section{Introduction}

Lyocell is the first ecofriendly regenerated cellulosic fibre. The other regenerated cellulosic fibres are Viscose, cellulose acetate etc. The lyocell is a Greek derived word came as Lyocell: lyo (Greek word) which is actually derived from the word 'lyein' which means dissolve and the word 'cell' derives as a short abbreviation from cellulose.

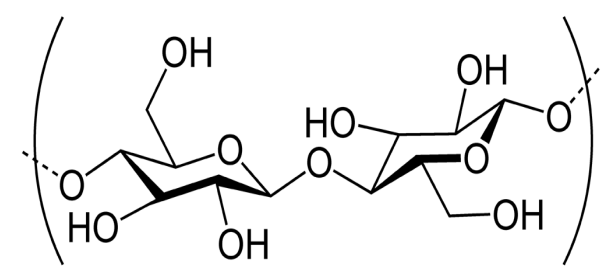

Figure 1. Cellulose, linear polymer $\beta-(1 \rightarrow 4)-D-$ glucopyranose [1]

The cellulose fibers produced by direct dissolution have the generic name of lyocell. The 'solvent spinning' means dissolving and spinning without the formation of a derivative. Solvent used for lyocell spinning - NMMO, Lyocell has all the benefits of being a cellulosic fibre, Fully biodegradable and Eco-friendly product[1-3].

\section{Preparation of the Raw Material: N-Methylmorpholone N-Oxide}

* Corresponding author:

kunalsingha28@gmail.com (Kunal Singha)

Published online at http://journal.sapub.org/ijme

Copyright (C) 2012 Scientific \& Academic Publishing. All Rights Reserved
- The N-methylmorpholine $\mathrm{N}$-oxide is abbreviated as NMMO

- The chemical formula of NMMO: 3 possible formulas of N-methylmorpholine-N- oxide[3-4]<smiles>CN1CCOCC1(C)N1CCOCC1</smiles><smiles>CN1CCOCC1[O-]</smiles><smiles>CN1CCOCC1</smiles><smiles></smiles>

Figure 2. Different possible chemical form (canonical structure) of $\mathrm{NMMO}[3]$

\subsection{Preparation $\mathrm{N}$-methylmorpholine $\mathrm{N}$-oxide}

Oxidation of ternary amine N- methylmorpholine with hydrogen peroxide gives $\mathrm{NMMO}[7]$.

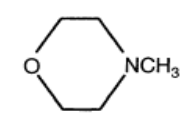

$\mathrm{N}$-methylmorpholine

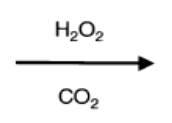

$\mathrm{N}$-methylmorpholine- $\mathrm{N}$-oxide
Figure 3. Preparation reaction of NMMO [7]

\subsection{Basic properties of $\mathbf{N}$-methylmorpholine $\mathbf{N}$-oxide}

- The molecular weight of NMMO $\left(\mathrm{C}_{5} \mathrm{H}_{11} \mathrm{~N}_{2} \mathrm{O}\right)$ is 115.2

- The melting point (anhydrous NMMO) is $170^{\circ} \mathrm{C}$

- The saturated vapour pressure is $0.35 \mathrm{~mm} \mathrm{Hg}$ at $25^{\circ} \mathrm{C}$, $6.5 \mathrm{~mm} \mathrm{Hg}$ at $91^{\circ} \mathrm{C}$;

- The initial decomposition temperature is $=100-110^{\circ} \mathrm{C}$, 
$\&$

- The intensive (turbulent) decomposition temperature is $=130-140^{\circ} \mathrm{C}$.

NMMO is hygroscopic material and forms hydrate;

- The monohydrate $\mathrm{C}_{5} \mathrm{H}_{11} \mathrm{~N}_{2} \cdot \mathrm{H}_{2} \mathrm{O}$ contains 13.5 wt. \% water, \& $\mathrm{Tm}=74-78^{\circ} \mathrm{C}$;

- The dihydrate $\mathrm{C}_{5} \mathrm{H}_{11} \mathrm{~N}_{2} \mathrm{O} .2 \mathrm{H}_{2} \mathrm{O}$ contains 23.5 wt. \% water, $\& \mathrm{Tm}=38-39^{\circ} \mathrm{C}[3]$.

\subsection{Dependence of NMMO Vapor Pressure \& its} Hydrates on Temperature

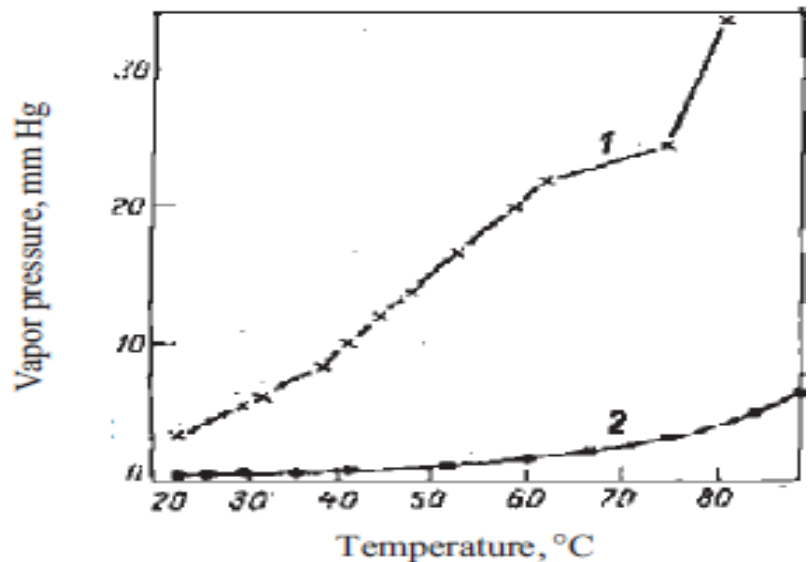

Figure 4. The Graph - (1) monohydrate (13.5\% water); (2) dihydrated NMMO[6,7]

\section{Phase Diagram of the NMMO Water System}

Phase diagram any material shows its states (equilibrium) under a spinning solution. It is very important for examining the technology and recycling of the solvent.

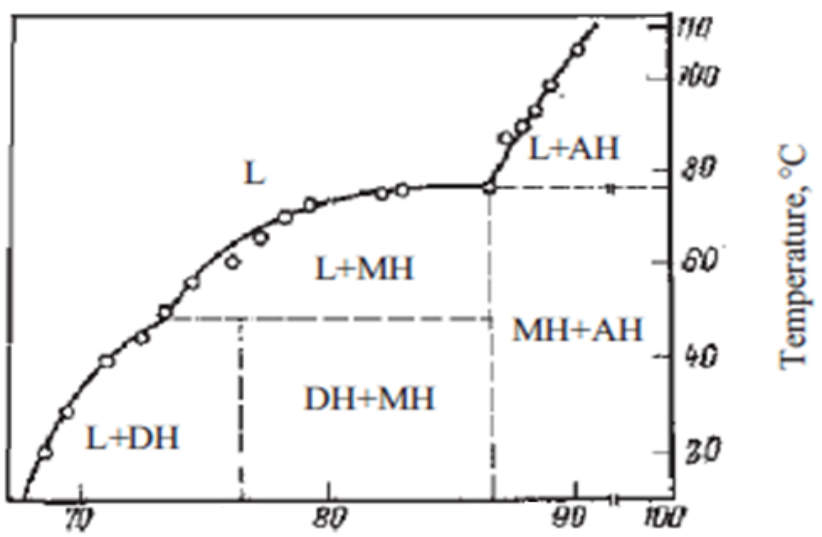

NMMO content, wt $\%$

Figure 5. Phase diagram of NMMO-Water system (for the monohydrate and anhydrous crystal) [8]

Regions of existence of: L- Liquid; L+DH-Liquid + dehydrate; $\mathrm{L}+\mathrm{MH}-$ Liquid + Monohydrate; $\mathrm{L}+\mathrm{AH}-$ Liquid + Anhydrous Crystal; $\mathrm{MH}+\mathrm{AH}-$ Monohydrate + Anhydrous Crystal[7].

\section{Life Cycle of Man-Made Cellulosic Fibers [2]}

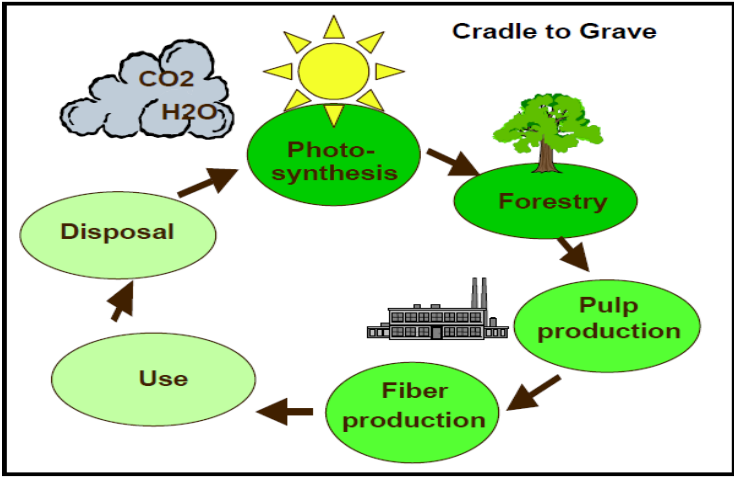

Figure 6. Life cycle of the lyocell fibers [2]

\section{Production of lyocell: Outline of the lyocell Process}

Raw Material - Wood Pulp and wood is easily available from nature and after collecting it we proceeds as per the flow-chart as below $[6,8]$;

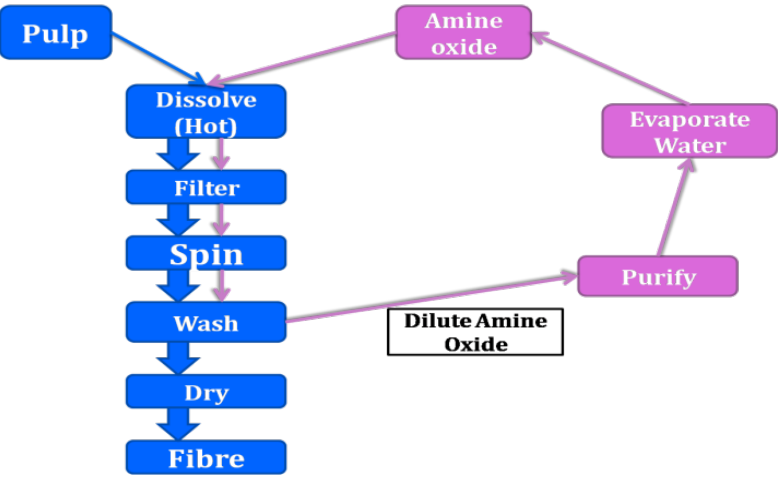

Figure 7. Schematic flowchart of the lyocell fiber production line[8]

\section{Production Technique of Lyocell [1]}

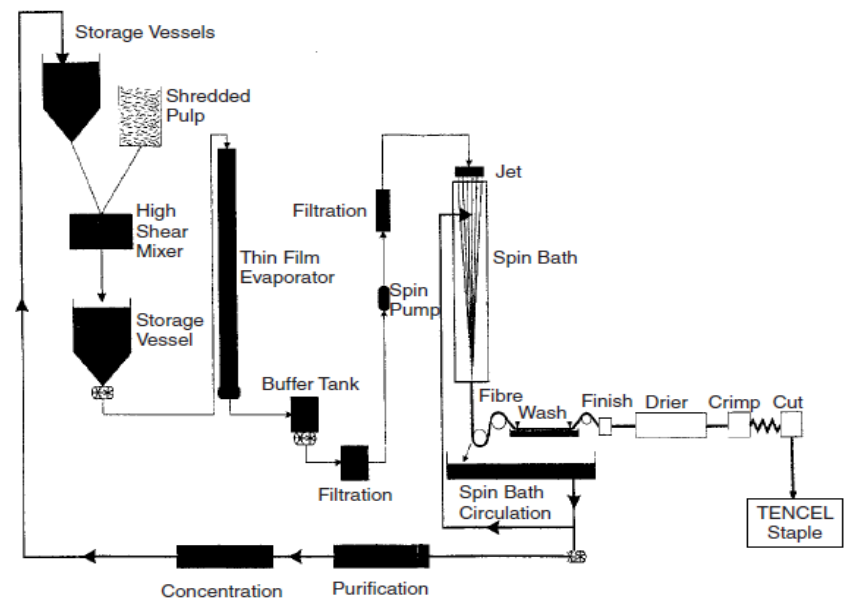

Figure 8. One typical example of lyocell production technique- the Acordis Tencel Process[1] 


\subsection{Process Involved in Production of Lyocell}

- Solution Making

- Solution Transport

- Solution Filtration

- Spinning

- Fiber Washing

- Fiber Treatment

- Fiber Drying

- Solvent Recovery

- Crimping, Cutting and Baling

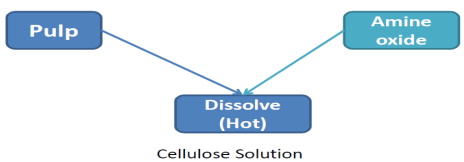

Figure 9. Process for making the mixature of pulp preparation of lyocell fiber[1]

At first we make the cellulosic material collected from nature and then make the pulp and premixPulp which is the

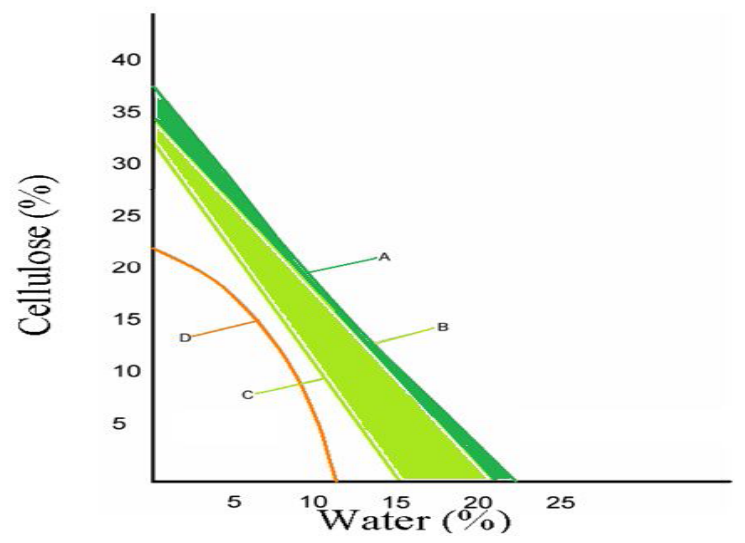

Principal raw material[1,9]. After that we cut pulp is mixed with a $76-78 \%$ amine oxide solution in water at $70-90^{\circ} \mathrm{C}$ and a small quantity of a degradation inhibitor \& other additives into the pulp prepared. Finally the resultant slurry consists of swollen pulp fibres and this final viscous solution is ready for lyocell spinning $[1,3,10]$.

\subsection{Solubility of Cellulose in the NMMO - Water System}

Generally the lyocell spinning is done at $95^{\circ} \mathrm{C}$, so it is very necessary to check the phase diagram of NMMO-water system used in spinning for a good rate of fiber production. The phase diagram of NMMO-water system has been shown as in below at $95^{\circ} \mathrm{C}$.

Right of line $\mathrm{A}=$ Undissolved cellulose fibers are bound to be present; between $\mathrm{A}$ and $\mathrm{B}=95 \%$ confidence that some undissolved cellulose fibres present in the solution; between $\mathrm{B}$ and $\mathrm{C}=$ Cellulose is soluble; between $\mathrm{C}$ and $\mathrm{D}=95 \%$ chance that crystals of undissolved NMMO will be present; left on line D = Anhydrous NMMO crystal[4,6-7,13].

\section{Swelling and Dissolution Mechanisms of Cellulose fibres in Function of the Solvent Quality}

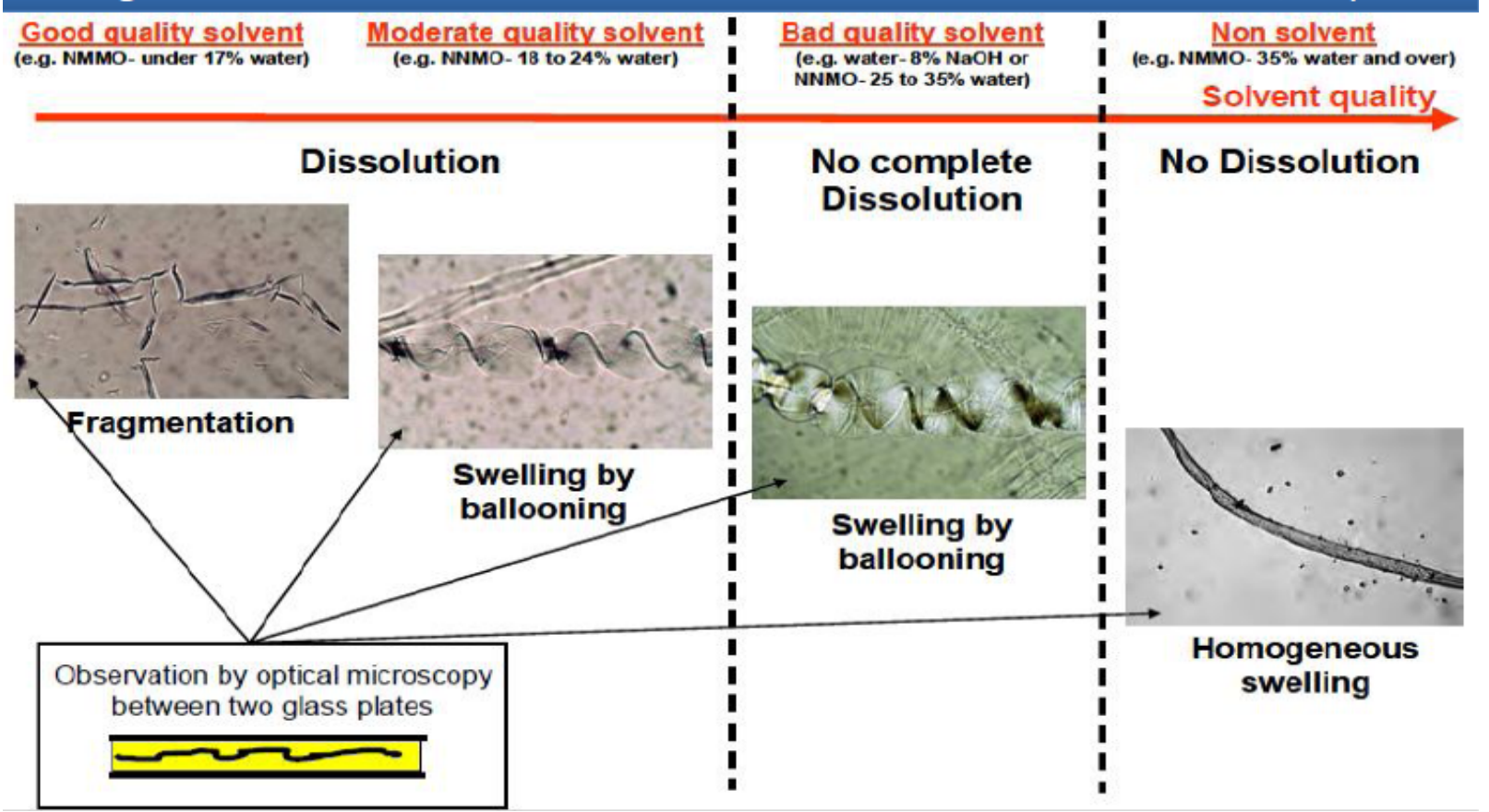

Figure 10. NMMO -Water - Cellulose Phase Diagram [5] 


\subsection{Process Involved in NMMO-water Solution Making}

- Evaporation of water from premix to make solution

- $10-18 \%$ cellulose content in solution.

- The evaporator vessel is operated under vacuum to reduce the temperature $\left(90-120^{\circ} \mathrm{C}\right)[1-3]$.

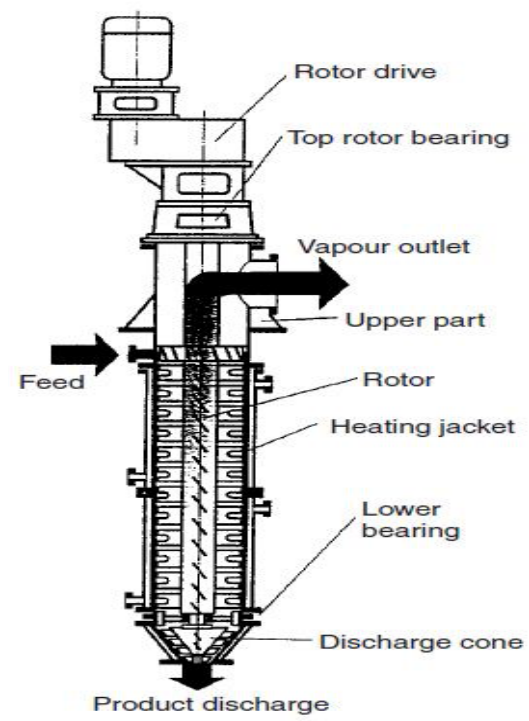

Figure 11. Thin-wall evaporator (Buss Filmtruder)[1]

This process is carried out in the machine called Filmtruder and in this whole reaction we need to to avoid the degradation of amine oxide for a proper spinning without any side-product reactions.

\subsection{Cross Section of the Film Extruder}

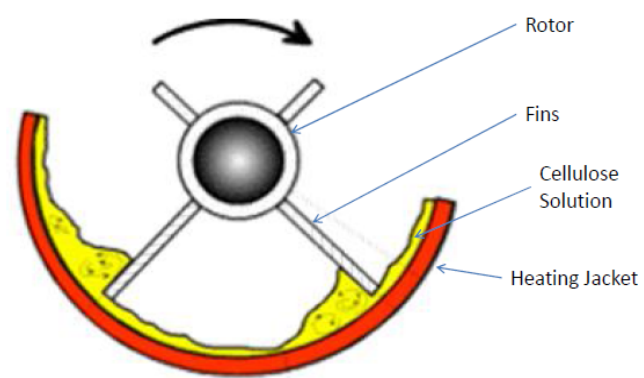

Figure 12. Different component of the film extruder used in lyocell spinning[4]

\subsection{Solution Transport}

\section{Filmtruder}

\section{Specialised Pumps}

\section{Filteration}

Figure 13. Steps involved in spinning solution (charge) transport in lyocell spinning

Sometime in special condition we use bursting discs - To release pressure in emergency or at extreme case[6].

\subsection{Solution Filtration}

It is necessary to remove impurities like sands \& ash prior to spinning because with that the impurities get introduced with pulp feedstock[6].

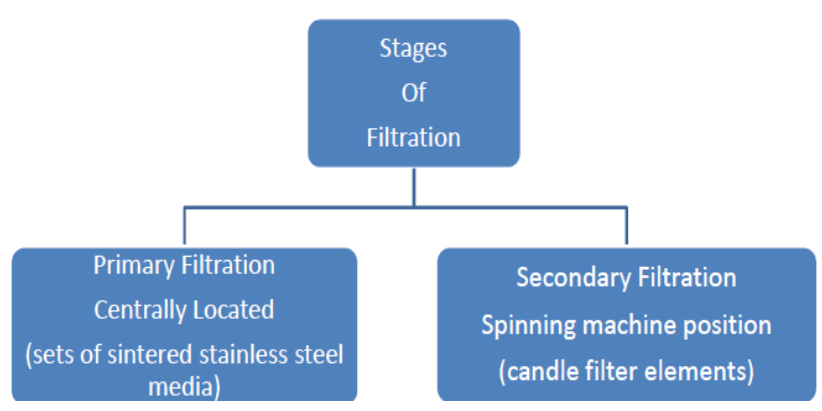

Figure 14. Steps involved in the filtration of the spinning solution[6]

\subsection{Spinning Technique}

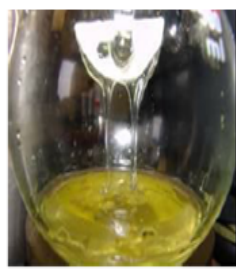

Good For Spinning
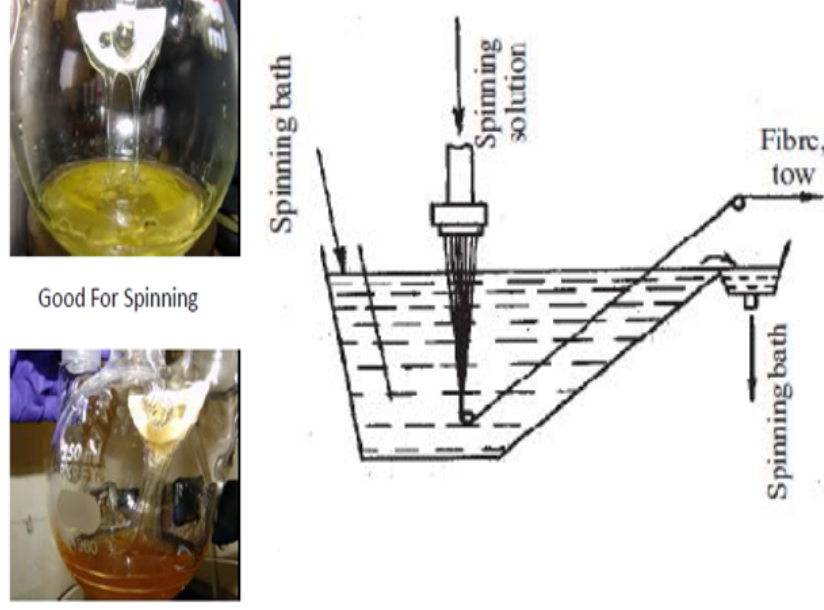

Not For Spinning

Figure 15. Schematic diagram of spinning fibers from NMMO-watercellulose solutions through an air gap[8-9]

\subsection{Orientation Occurs During Lyocell Spinning[11,12]}
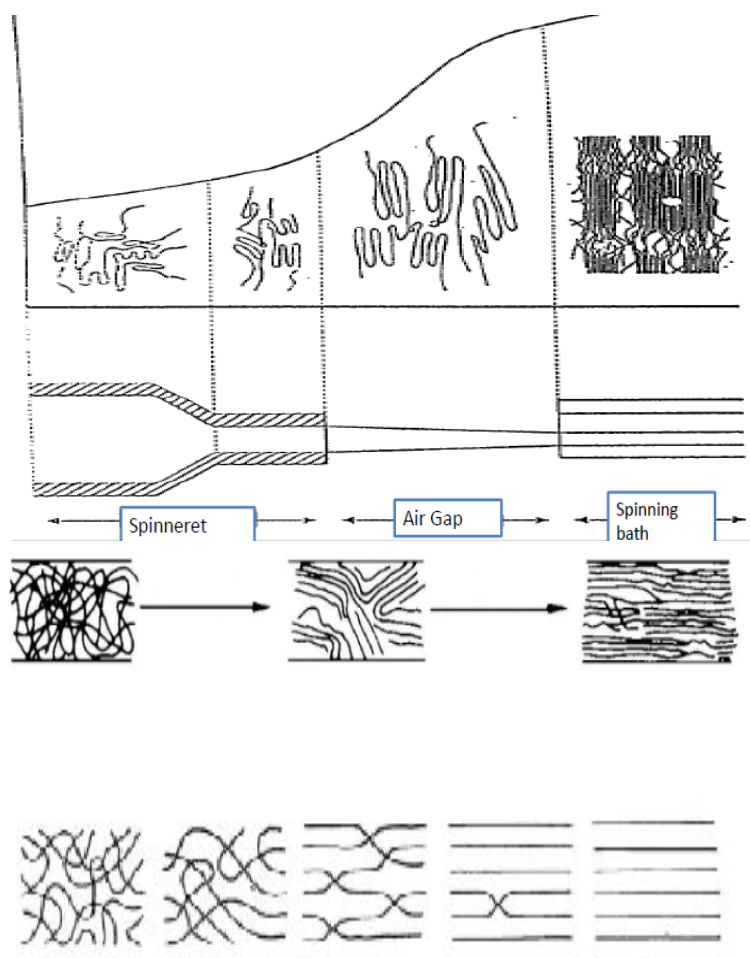

Figure 16. Effects of the air gap in the lyocell fiber orientation[11] 


\section{Fiber Washing}

For washing the fiber prepared after spinning firstly we make one large tow band is made from smaller tow and then the solvent is washed from the fiber with hot demineralised water in a series of wash baths[1].

\section{Fibre Treatment}

Several treatments can be given after fiber washing like

- Bleaching if required.

- Soft finish treatment

- Antistat finishing

- Crimping and cutting to the desired length

- Other specific fiber treatment to have specific properties[5]

\section{Fiber Drying}

Generally we use the conventional fiber drum dryers

- Series of perforated drums[5]
- Steam heated air is sucked through the fiber as it passes over the drums and exhausted to atmosphere[7]

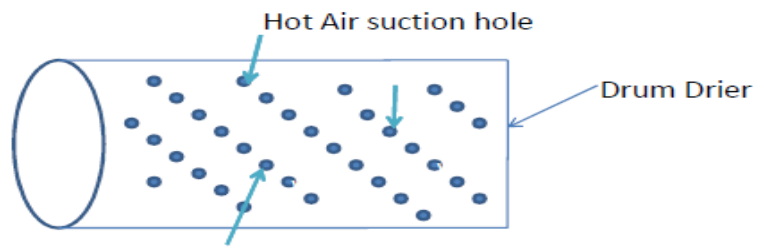

Figure 17. Schematic diagram of fiber drying system[7]

\section{Crimping, Cutting and Bailing}

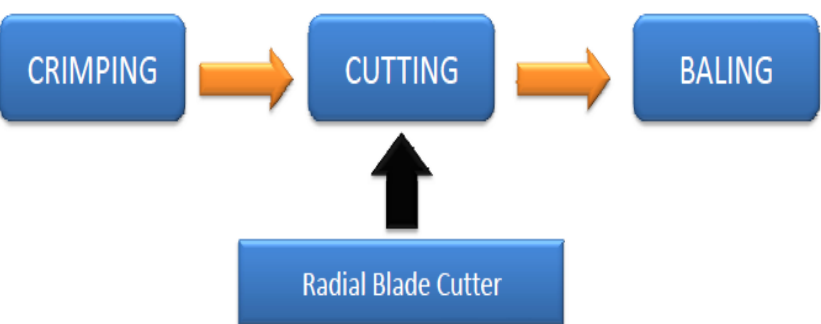

Figure 18. Flowchart involved in lyocell fiber processing[13]

Table 1. Comparison of lyocell fiber with others natural fibers[3]

\begin{tabular}{|c|c|c|c|c|c|}
\hline Indexes & Lyocell & \multicolumn{2}{|c|}{ Viscose fiber } & Cotton & Flax \\
\hline Cellulose & & Ordinary & High modulus & & \\
\hline Composition, \% & 100 & 100 & 100 & $97-98$ & $80-85$ \\
\hline Lignin & - & - & - & - & $3-5$ \\
\hline Shape of fibrils & Drawn & Drawn & Drawn & Spiral & Spiral \\
\hline Tilt of fibrils, deg. & $8-10$ & $10-20$ & $8-10$ & $25-45$ & $3-10$ \\
\hline Moisture content, $\%$ & $11-13$ & $13-14$ & $12-13.5$ & $7-9$ & $10-13$ \\
\hline Strength, ${ }^{*}$ cN/tex & $35-47$ & $20-26$ & $32-36$ & $25-40$ & $40-55$ \\
\hline Elongation,*\% $\%$ & $11-16$ & $18-25$ & $12-15$ & $8-10$ & $2-3$ \\
\hline Deformation modulus, $*$ GPa & $8-10$ & $34-5$ & $5-6.5$ & $5-9$ & $30-50$ \\
\hline Deformation modulus in wet state, GPa & $3-4.5$ & $0.6-1$ & $1.5-2$ & - & - \\
\hline
\end{tabular}

\section{Structure of the Lyocell Fiber}
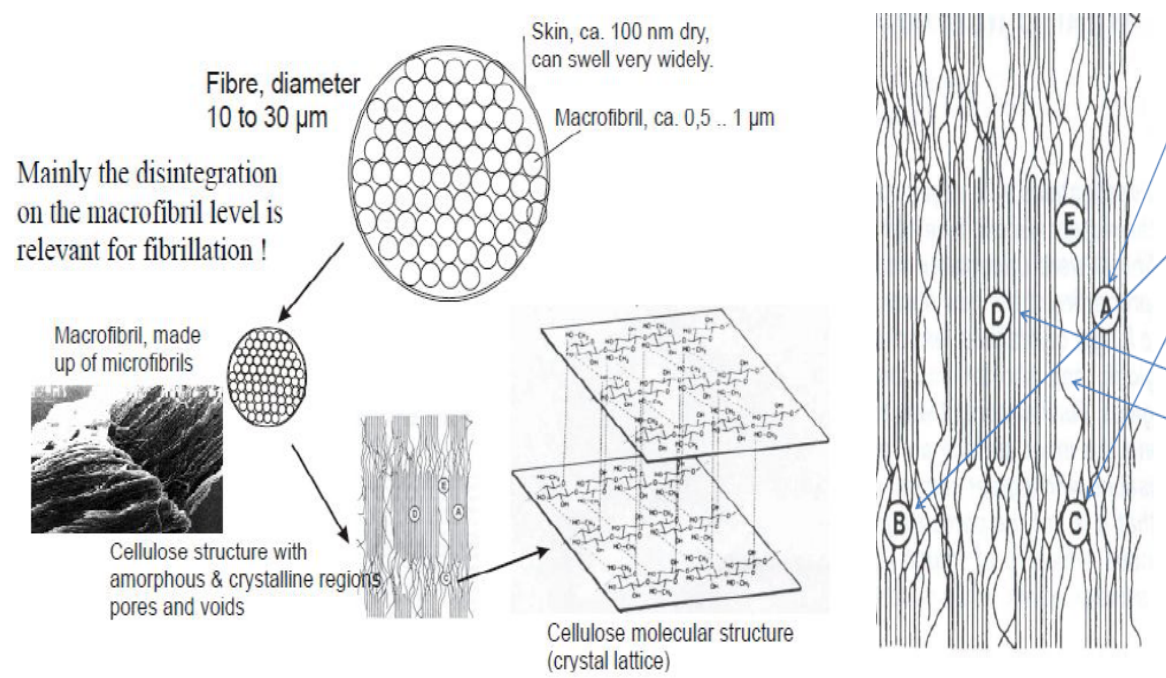

(A) High crystallinity, high longitudinal orientation of crystallites

(B) High amorphous orientation

(C) Low lateral cohesion between fibrils

(D) Low extent of clustering

(E) Relatively large void (pore) volume

Figure 19. Fiber model for lyocell fiber[14,13,17]

Proposed Fibre Model - Fringed Fibrillar Model 


\subsection{The Internal Pore Structure}

By applying TEM on ultra-thin cross-sections of fibers we find the nano-pores $(20 \mathrm{~nm})$ in the bulk of the fiber with the slight gradient in pore density. There also has a very porous skin layer over the fiber surface[15].

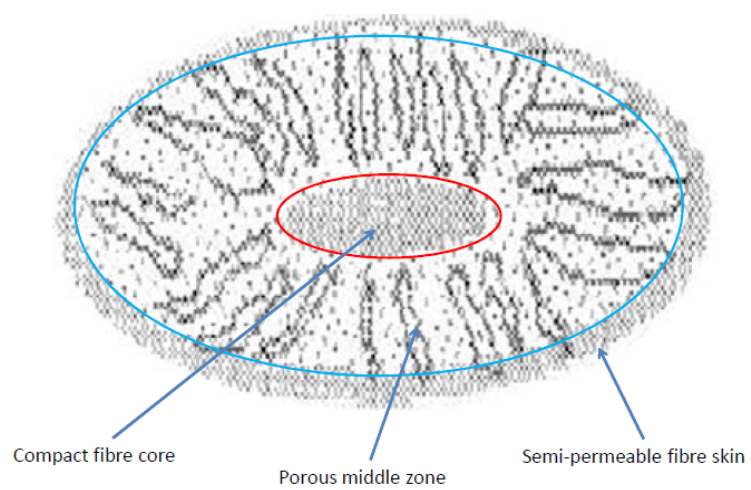

Figure 20. A structure model of regenerated cellulose materials formed by the lyocell process under the conditions of lyocell fiber spinning[15]

\section{Fibrillation}

Fibrillation can be defined as the longitudinal splitting of a single fibre filament into microfibres. The splitting occurs as a result of wet abrasion, particularly against metal and gives a frosty appearance[16-18]. The Fibrillation is measured in term of Fibrillation Index (F.I) and mathematically, fibrillation index is given as sum of the lengths of the fibrils (1) over a length of fiber (L).

$$
\text { F.I. }=\Sigma l / \mathrm{L}
$$

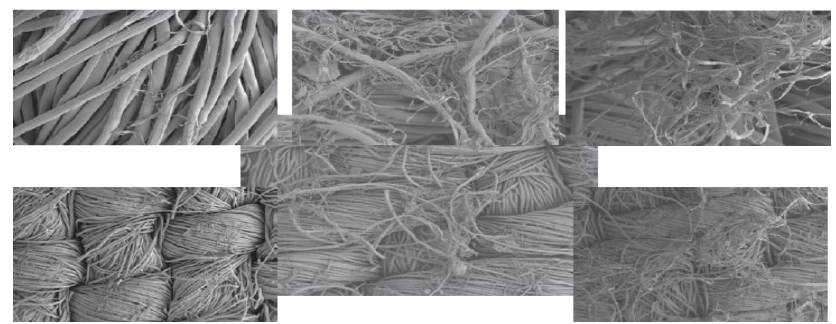

Figure 21. SEM pictures of fibrillated lyocell fiber

\subsection{Cause of Fibrillation}

- Fiber + Water $=$ Fiber Swelling

- Fiber Swelling + Mechanical Abrasion = Fiber Fibrillation

- Fibrillation get accelerated with

- High PH

- High temperature,

- Lack of lubrication,

- Vigorous machine action and so on

- Fibrillation increases due to the swelling and low lateral cohesion between the fibrils of the fiber[17].

\subsection{Types of fibrillation}

- primary Fibrillation

- secondary Fibrillation[17]

\subsection{Fibrillation Control}

- Application of enzymes

- Application of easy care resins

- Application of cross-linking chemicals Process[16,18]

\section{Advantages of Lyocell Fiber}

- Biodegradable fiber

- Breathable

- Peach Skin touch can be imparted

- Short production cycle. No ageing and ripening. Dissolution and spinning of cellulose can be done in $5 \mathrm{hrs}$.

- Eco-friendly. No toxic by-products or gases are produced (as CS2 and $\mathrm{H} 2 \mathrm{~S}$ in viscose process).

- Recovery of NMMO is very high, almost $99.5 \%$.

- Highly concentrated cellulose solutions can be made $(25-35 \%)$.

- Fibre can be spun at relatively higher speeds (150-300 mpm).

- Better mechanical properties, especially in wet state.

- All the effluent produced is non hazardous.

- Modification of solution containing cellulose can be done by adding other polymers like cellulose Acetate or polyvinyl alcohol[1-4]

\section{Limitations}

- NMMO is an excellent oxidizer and slowly oxidise the cellulose during the process.

- NMMO is highly corrosive.

- Increased consumption of NMMO, increases degradation of cellulose (DP loss) because NMMO is an oxidizer (prominent at elevated temperature).

- At temperatures above $150^{\circ} \mathrm{C}$, it undergoes highly exothermic decomposition that can be catalysed by copper or iron ions. This can be explosive.

- Increased chromophore formation, causes a number of secondary, undesired side effects such as reduced bleachability of the fiber material[3-4].

\section{Development}

- Continuous Dissolution Process of Cellulose in NMMO

- Lenzing Lyocell® LF - Low Fibrillation Fibre

- Lyocell fiber from Sawdust

- Spun dyed lyocell fiber

- Flame Retardant Lyocell fiber

- Antimicrobial Lyocell fiber

- Lyocell fiber for tyre cord application and so on[1,4].

\section{Applications of Lyocell}

Lyocell fiber is widely used in apparel application, paper industry, nonwoven field, blend fabric making etc[1-3]. 


\section{Conclusions}

The lyocell fiber is widely used in the modern interdisciplinary application over in the appliled field. The spinning process and proper analysis of the lyocell fiber can save our costs, quality and fiber dimension and properties. The various development is also can be achieve by the accurate idea over the fiber morphology and which can provides us a suitable pathway to make this lyocell fiber as a remarkable substitute over natural cotton fiber.

\section{REFERENCES}

[1] C. Wooding; Lyocell: The Production Process and Market Development, Regenerated Cellulose Fibres, Chapter 4, Ed. Third edition, Woodhead Publishing Ltd (2001).

[2] M. Dever, J. Billie, Collier, S. Petrovan, J.R. Collier; International Textile \& Apparel Association, 7, 104 (2005).

[3] K.E. Perepelki; Fibre Chemistry, 11 (2) 34 (2007).

[4] E. Borbely; Acta Polytechnica Hungarica, 13, 147 (2008).

[5] M.N. Moigne; Ecole Doctorale: Sciences Fondamentales et Appliquées. Doctoral theses, Mines Paris Tech. (2008).

[6] V.B. Gupta and V.K Kothari, Rayon Fibre, Chapter 17, Ed. First edition, Manufactured Fibre Technology, Chapman \& Hall (1997).

[7] H.P. Fink, P. Weigel, H.J. Purz, J.Ganster; Prog. Polymer
Science, 5(2), 625 (2001).

[8] T. Hongu, G.O. Philips, New Fibers, Chapter 2, Ed. Second edition, Woodhead Publication (1997).

[9] Gannon et al, Lyocell Fibre and A Process for its manufacture, Patent No. 6042769, 28, (March 2000).

[10] H.J. Lee, Master Thesis in Textile science \& Tech., Graduate Faculty of North Carolina State University, North Carolina (2007).

[11] Z. Lewandowski; Journal of Applied Polymer Science, 81(14), 182 (2001).

[12] C. Andreoli, F. Freti; Foundazione Acimit, 8(2), 169 (2004).

[13] D.B. Kim, W.B Lee, S.M. Jo, Y.M. Lee, B.C. Kim; Journal of Applied Polymer Science, 6(3), 239 (2002).

[14] K.C. Schuster, P. Aldred, M. Villa, M. Baron, O. Biganska; Lenzinger Berichte, 85, 622, 2003.

[15] M.A. Rous, E. Ingolic, K.C. Schuster; Cellulose, 23, 214, 2006.

[16] F. Carrillo, X. Colom, J. Valldeperas, D. Evans, M. Huson, J. Church; Textile Research Journal, 76 (9), 781 (2003).

[17] P. Lodha, B. Kapoor, T. Mahajan; A Lyocell Fibre with Modified Property and A Process for making therefor, Aditya Birla Science \& Technology Co. Ltd., International Publication (WO 2009/063479 A2) (2009).

[18] D.B. Kim, J.J. Pak; Textile Research Journal, 8(3), 235 (2005). 